\title{
Correction to: Earthquake and Disaster Risk: Decade Retrospective of the Wenchuan Earthquake
}

\author{
Yong-Gang Li
}

Correction to:

Y.-G. Li (ed.), Earthquake and Disaster Risk:

Decade Retrospective of the Wenchuan Earthquake, https://doi.org/10.1007/978-981-13-8015-0

The original version of the book was inadvertently published with an incorrect figure in Chapters 2, 3 and 6. Figures 2.2, 3.1 and 6.1 have been replaced with the correct figure in the updated version.

The updated versions of these chapters can be found at https://doi.org/10.1007/978-981-13-8015-0_2

https://doi.org/10.1007/978-981-13-8015-0_3

https://doi.org/10.1007/978-981-13-8015-0_6

(C) Higher Education Press and Springer Nature Singapore Pte Ltd. 2019 